\title{
Corrigendum
}

\section{High expression of CXCR4 may predict poor survival in resected pancreatic adenocarcinoma}

\author{
R Maréchal, P Demetter, N Nagy, A Berton, C Decaestecker, M Polus, J Closset, J Devière, I Salmon \\ and J-L Van Laethem
}

British Journal of Cancer (2010) 103, 930. doi:I0.1038/sj.bjc.6605894 www.bjcancer.com

(c) 2010 Cancer Research UK

Correction to: British Journal of Cancer (2009) 100, 1444-1451. doi:10.1038/sj.bjc.6605020

Upon publication of this paper in 2009, the authors noticed two errors - one in the abstract and one within the Results section.

On page 1444 (Abstract), the seventh sentence should read as follows:

'In a combining analysis, patients with a $\mathrm{CXCR} 7^{\text {high }} / \mathrm{CXCR} 4^{\text {high }}$ tumour had a significantly shorter DFS and OS than patients with a CXCR $4^{\text {low }} /$ CXCR7 ${ }^{\text {low }}$ tumour'.
On page 1447 (Results), the first sentence of the section entitled 'CXCR4 and CXCR7 coexpression and patients outcome' should read as follows:

'Interestingly, patients with $\mathrm{CXCR} 4^{\text {low }} / \mathrm{CXCR} 7^{\text {low }}$ tumour expression have a significantly prolonged DFS and OS than those patients with a CXCR $4^{\text {high} / C X C R 7 ~}{ }^{\text {high }}$ tumour expression (Figure 3C; median DFS: 15.80 months (95\% CI: 10.43-21.17) vs 7.62 (2.97-12.27), $P=0.037$; median OS: not reached vs 9.69 (95\% CI: $5.13-14.07), P=0.001)$ '. 